\title{
Erratum to: Two-component signal transduction in Corynebacterium glutamicum and other corynebacteria: on the way towards stimuli and targets
}

Michael Bott • Melanie Brocker

Published online: 27 September 2012

(C) Springer-Verlag Berlin Heidelberg 2012

Erratum to: Appl. Microbiol. Biotechnol. 94: 1131-1150 DOI 10.1007/s00253-012-4060-x

The published version of this article unfortunately contains mistakes. In Figs. 2, 3, 4, 5 and 6, the phosphorylated aspartate residue of the response regulators is wrongly indicated with an "A" instead of a "D". The correct Figs. 2, 3, 4, 5 and 6 are the following:

The online version of the original article can be found at http://dx.doi.org/ 10.1007/s00253-012-4060-x.

M. Bott $(\bowtie) \cdot$ M. Brocker $(\bowtie)$

Institut für Bio- und Geowissenschaften, IBG-1: Biotechnologie,

Forschungszentrum Jülich,

52425 Jülich, Germany

e-mail: m.bott@fz-juelich.de

e-mail: m.brocker@fz-juelich.de 
Fig. 2 Control of citrate transport by the CitAB twocomponent system of $C$. glutamicum. The target genes shown in green are activated in the presence of extracellular citrate and encode two distinct citrate transport systems

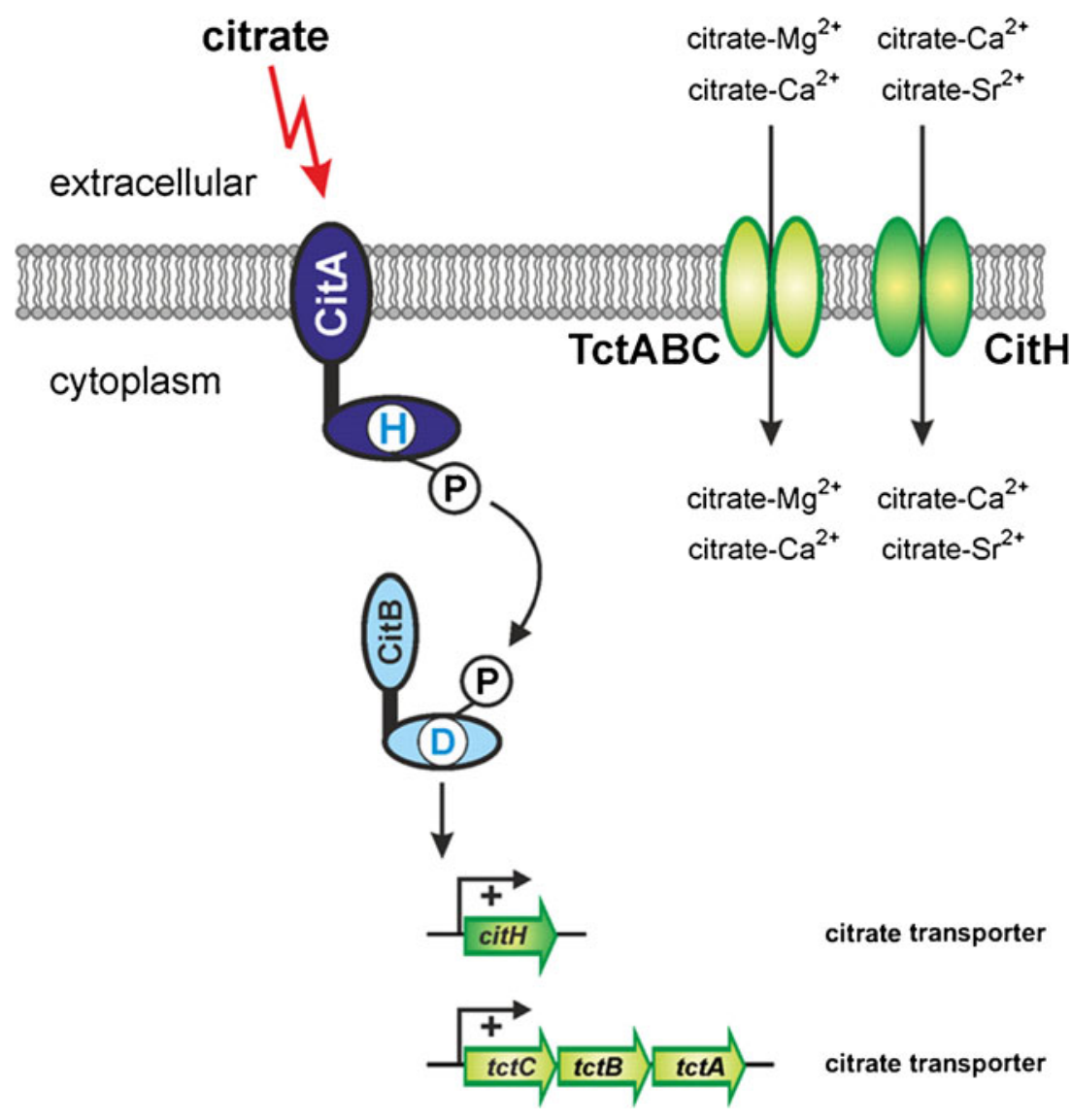




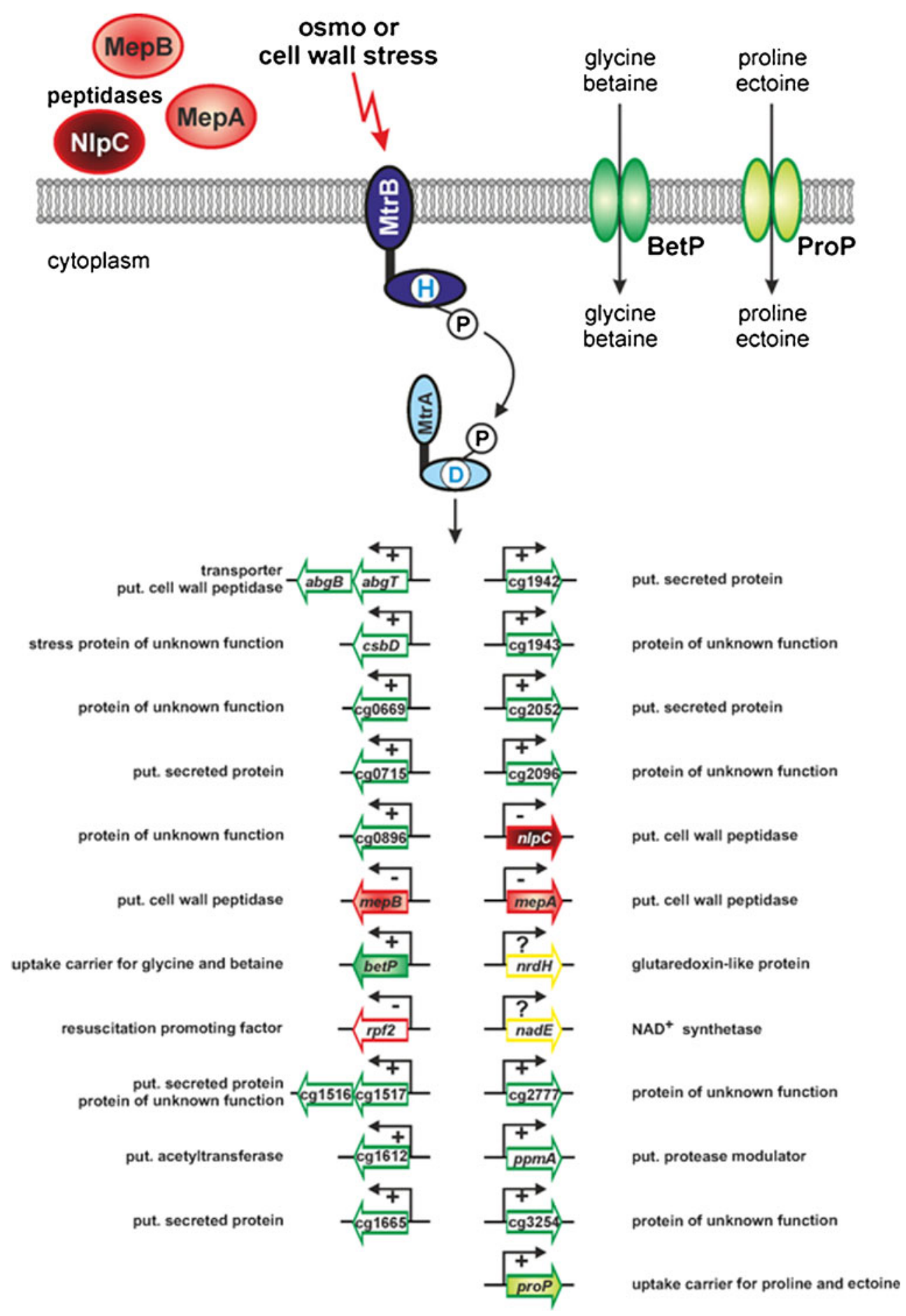

Fig. 3 Regulon of the MtrAB two-component system of C. glutamicum showing its involvement in osmoregulation and cell wall metabolism. Genes shown in red are repressed and genes shown in green are activated by MtrA. Target proteins with known function are indicated.

For genes highlighted in yellow a binding of the response regulator MtrA upstream of these genes was observed, but the mRNA level of the genes was not altered in mutants lacking $m t r A B$ or $m$ tr $A$ 


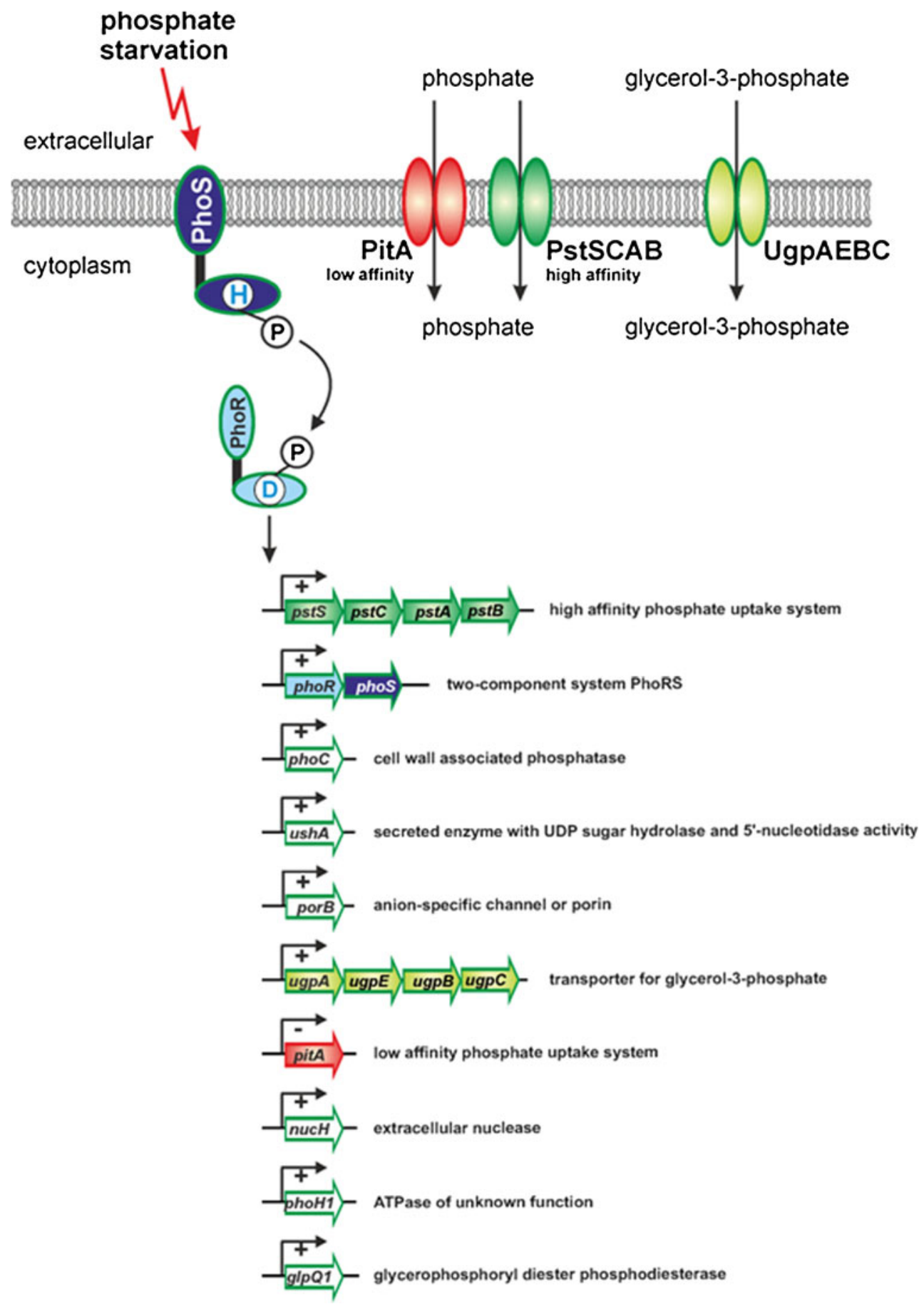

Fig. 4 Role of the PhoRS two-component system of C. glutamicum in phosphate starvation. Genes shown in green are activated by PhoR, the pitA gene shown in red is repressed by PhoR. The function of some target proteins is indicated 
Fig. 5 Response to copper stress by the CopRS twocomponent system of C. glutamicum. All genes displayed are activated by CopR in response to elevated copper concentrations

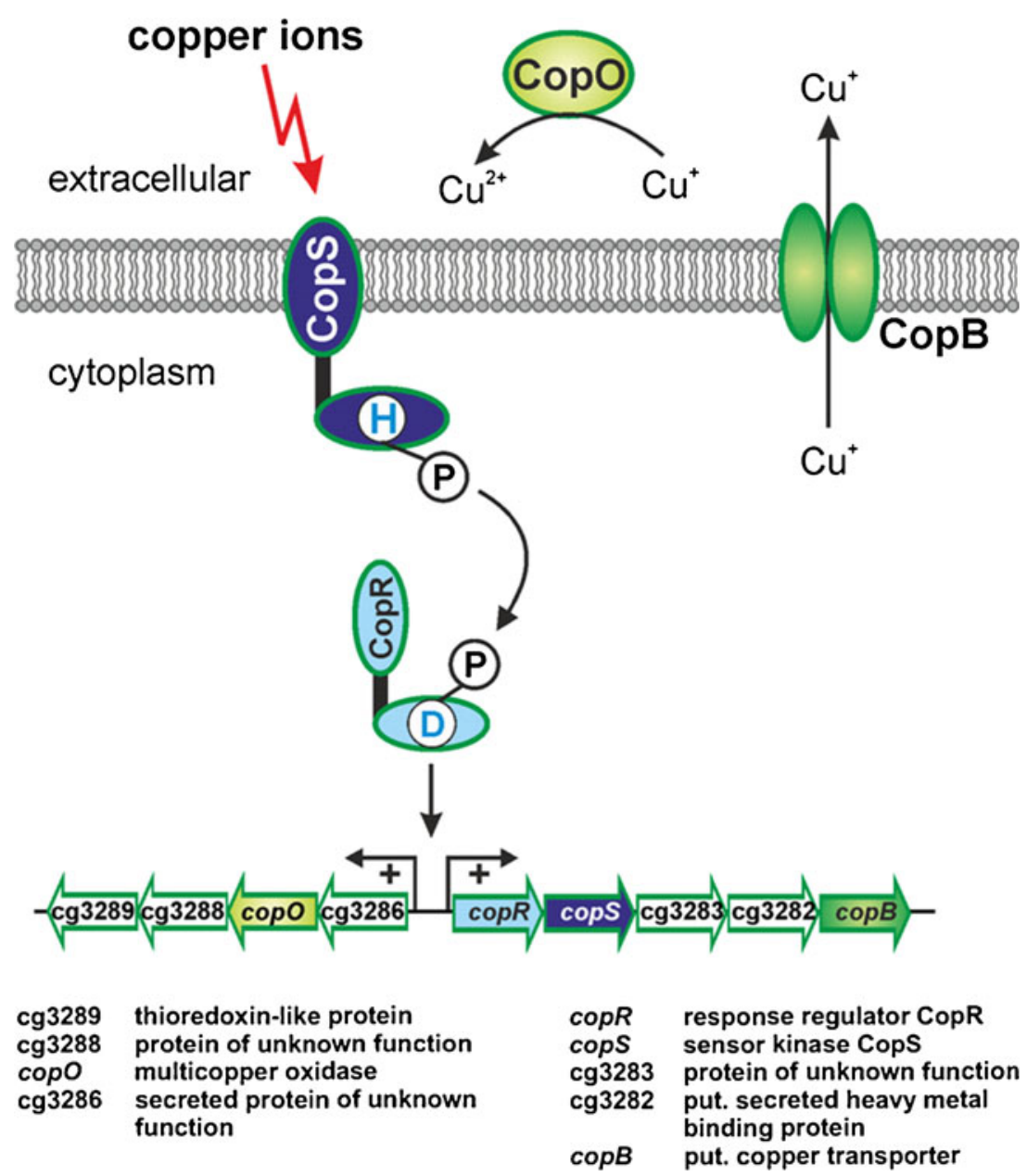




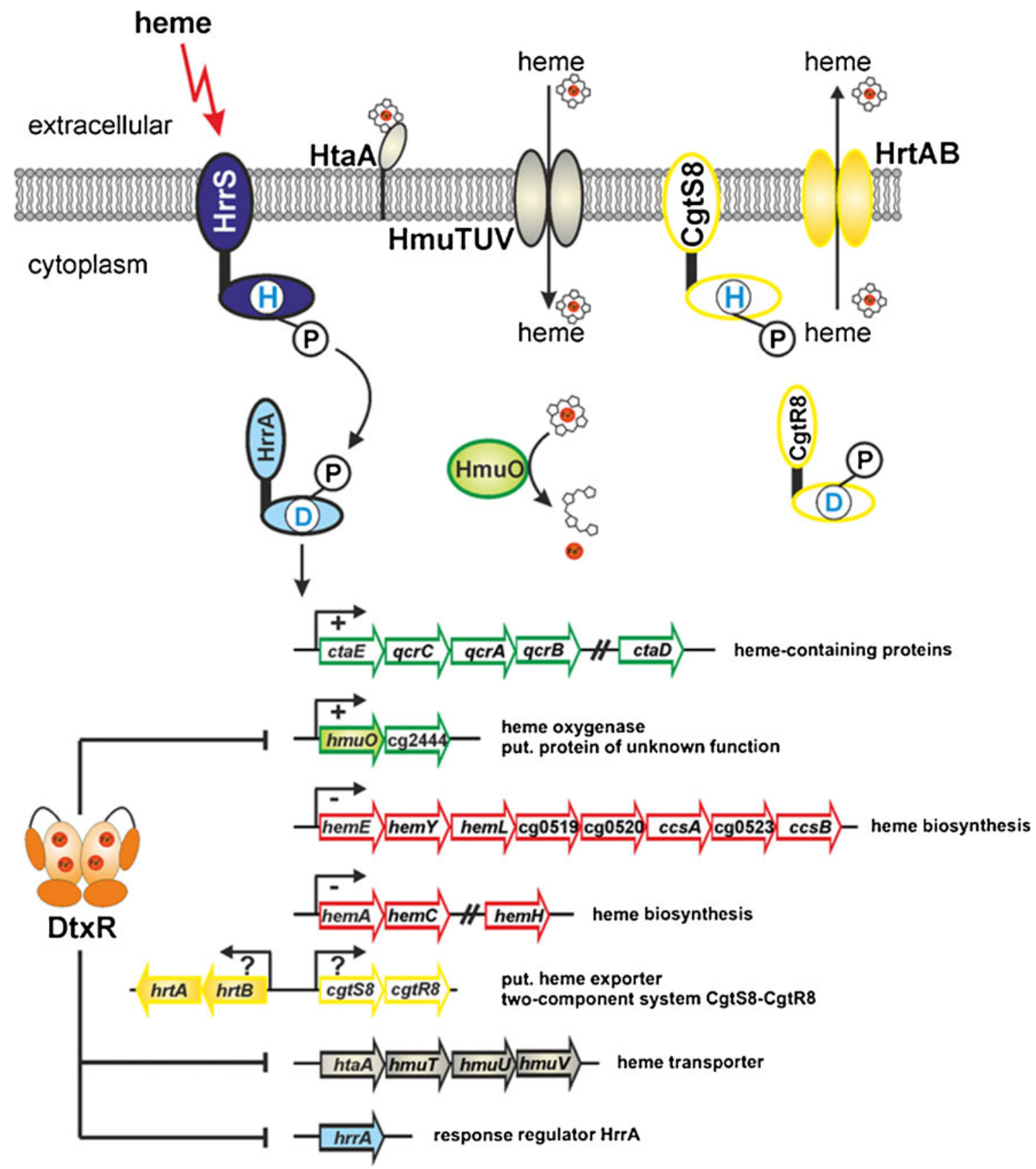

Fig. 6 Control of heme homeostasis by the HrrSA two-component system of $C$. glutamicum. The genes shown in green are activated by HrrA, the genes encircled in red are repressed by HrrA. The genes shown in black, which encode an ABC transporter for heme uptake, are not regulated by HrrA. Rather, they are repressed under iron excess by DtxR, similar to some of the HrrA target genes. For genes highlighted in yellow a binding of the response regulator HrrA upstream of these genes was observed. It is still unclear if binding of HrrA to this region leads to activation or repression of one or both of the divergently orientated operons. The CgtSR8 two-component system possibly activates expression of the $h r t B A$ genes, which encode a putative heme exporter, in response to elevated heme concentrations. Note that alternative names exist for some of the genes involved in heme biosynthesis: hem Y/hem $G, \operatorname{cg} 0520 / \operatorname{cs} X / \mathrm{res} A, \operatorname{ccs} A / \operatorname{ccd} A, \operatorname{cg} 0523 / \mathrm{ccs} B / \mathrm{res} B$, $\operatorname{css} B / \operatorname{ccs} A /$ res $C$ 